https://doi.org/10.34024/prometeica.2021.22.11521

\title{
LA DENSIDAD DE LAS IMÁGENES
}

ESPECTÁCULO E HISTORIA EN HANS BLUMENBERG Y GUY DEBORD

THE DENSITY OF THE IMAGES

Spectacle and history in Hans Blumenberg and Guy Debord

A DENSIDADE DAS IMAGENS

Espetáculo e história em Hans Blumenberg e Guy Debord

\author{
Pedro García-Durán \\ (Universitat de València) \\ trucoso@hotmail.com
}

Recibido: 05/12/2020

Aprobado: 23/12/2020

\begin{abstract}
RESUMEN
El presente artículo trata de pensar los diagnósticos de Guy Debord, desarrollados en torno al concepto de "espectáculo", por medio de las categorías y descripciones de la historia de la significatividad que se despliegan en la obra de Hans Blumenberg. Esta relación permite comprender la actualidad del andamiaje teórico de este último no sólo como un conjunto de herramientas de descripción histórica, sino en tanto aportaciones valiosas para analizar y comprender las formas actuales de elaboración de la experiencia y del significado. Por otra parte, esta confluencia también permite medir la validez y profundidad del diagnóstico que pronunciase el líder de la Internacional Situacionista en La sociedad del espectáculo, así como señalar las diferencias que separan a ambos autores y las aporías que se expresan en sus respectivos pensamientos. En definitiva, este artículo buscará aportar elementos que hagan posible pensar, desde un punto de vista crítico, las formas de construcción de la significatividad en un momento en el que éstas también se ven sometidas a procesos de tecnificación y espectacularización.
\end{abstract}

Palabras clave: alienación. poder. historicidad.

\section{ABSTRACT}

This paper tries to think Guy Debord's diagnoses, developed around his concept of "spectacle", through the categories and descriptions of Hans Blumenberg's studies on the history of significance. This relationship allows us to understand the actuality of the latter's theoretical framework not only as a set of historical, descriptive tools but also as valuable contributions to analyze and understand current forms of elaboration of experience and meaning. On the other hand, this confluence can also be useful to measure the validity and depth of the diagnosis made by the leader of the Situationist International in The Society of the Spectacle, as well as to point out the differences that separate both authors and the aporetical experiences expressed by their respective thoughts. Ultimately, this article seeks to provide elements that make it possible to think, from a critical point of view, the forms of 
construction of significance at a time when they are also subjected to processes of technification and spectacularization.

Keywords: alienation. power. historicity.

\section{RESUMO}

Este artigo busca pensar os diagnósticos de Guy Debord, desenvolvidos em torno do conceito de "espetáculo", por meio das categorias e descrições da história da significação que se desdobram na obra de Hans Blumenberg. Essa relação permite compreender a atualidade do arcabouço teórico deste último, não apenas como um conjunto de ferramentas de descrição histórica, mas também como contribuições valiosas para analisar e compreender as formas atuais de elaboração da experiência e da significação. Por outro lado, essa confluência também permite medir a validade e a profundidade do diagnóstico feito pelo dirigente do Situacionista Internacional em A Sociedade do Espetáculo, bem como apontar as diferenças que separam os dois autores e as aporias que se expressam em seus respectivos pensamentos. Em última instância, este artigo buscará fornecer elementos que possibilitem pensar, de um ponto de vista crítico, as formas de construção de significados em um momento em que também estão sujeitas a processos de tecnificação e espetacularização.

Palavras-chave: alienação. poder. historicidade.

\section{Introducción}

Un diálogo entre Hans Blumenberg y Guy Debord como el que este escrito tratará de provocar puede parecer forzado en vista de las distancias personales, políticas e, incluso, estilísticas que los separaban. No es aventurado suponer que, de haberse conocido, no habrían sentido sino rechazo e, incluso, desprecio el uno por el otro. El revolucionario irredento surgido de la vanguardia artística expresó en muchas ocasiones su repulsa hacia el ideal de académico teórico que Blumenberg encarnaba de forma consciente y complacida. ${ }^{1}$ Éste, por su parte, nunca dejó pasar la ocasión de ironizar sobre la frivolidad de los movimientos revolucionarios y estudiantiles de los sesenta, para los cuales Debord se erigió en profeta. ${ }^{2}$ Estas diferencias son tan obvias y profundas que no pueden dejar de reflejarse en sus respectivas obras. No obstante, aunque nos haremos cargo por extenso de ellas, puede detectarse un núcleo común relevante alrededor del cual girará este artículo y que se encontraría en torno a la preocupación compartida por las consecuencias de un proceso de negación de la historicidad que se habría acelerado en el horizonte de una sociedad espectacular tecnificada. Una cuestión que surge de la mutua convicción en la identidad entre ser humano e historicidad. Dicha creencia, por su parte, no conlleva sustancialismo o esencialismo histórico alguno, sino que, como se mostrará, incide en el carácter de proceso temporal plástico que sólo puede ser unificado mediante el trabajo o actividad humanos. Desde este punto de partida, ambas interpretaciones muestran aspectos de peso que pueden ser compatibles e, incluso, complementarios. En definitiva, la interacción entre estas posturas permite pensar cuestiones de peso referentes a la historia y la temporalidad y a la experiencia humana de las mismas que son candentes hoy

\footnotetext{
${ }^{1}$ El desprecio de Debord por los académicos se ve reflejado en sus críticas al estructuralismo al cual califica de "pensamiento universitario de mandos intermedios tempranamente satisfechos" o de "pensamiento garantizado por el estado" (Debord, 1999: 164). No obstante, más allá de la crítica debordiana a cualquier forma de relación acomodaticia con el orden, su rechazo a esta corriente tenía una fuerte motivación teórica que bien podía compartir con Blumenberg: la ceguera histórica de su método.

${ }^{2}$ La participación de Debord y la Internacional Situacionista en las revueltas de Mayo del 68 les confirieron una notable publicidad a la que se añadió un cierto halo profético dado que fueron de los pocos que apostaron, durante los años anteriores, por la posibilidad de un movimiento revolucionario en el seno de las sociedades occidentales (Jappe, 1998: 113 y ss.). Por su parte, Blumenberg siempre se mostrará irónico respecto a los movimientos estudiantiles señalando, como veremos, su origen en el aburrimiento de una vida en exceso cómoda. Un ejemplo paradigmático de este desdén puede apreciarse en la pregunta que le formula a Jacob Taubes acerca de su entusiasmo ante una manifestación en Berlín en el 68 y su empatía hacia las víctimas de la represión ulterior: "Él era simplemente un espectador de una manifestación y, aun así, un excelente aspirante al martirio. [...]- ¿En nombre de qué verdad? - le pregunté. Él convirtió el hecho de que se haya de sufrir por la verdad en que deba ser verdadero aquello por lo que se sufre" (Blumenberg- Taubes, 2013: 291).
} 
en día ya que entroncan con la alienación del particular respecto al colectivo, el ejercicio y la justificación del poder $\mathrm{y}$, en un aspecto más profundo, el problema del reconocimiento del individuo en su propia existencia.

Así, el diagnóstico que Debord realiza con su célebre concepto de "espectáculo" permite concretar la forma en que se tecnifica y se detiene el proceso de unificación de la experiencia a través del tiempo, el esfuerzo por dotarla de coherencia y sentido, aportando una dimensión crítica que no aparece, al menos de forma explícita, en la obra de Blumenberg. Por otra parte, la pormenorizada interpretación antropológica de la historia como historia de la producción de significatividad que lleva a cabo Blumenberg en su obra aporta conceptos y descripciones que cuadran con la denuncia de Debord y pueden contribuir a darle un mayor desarrollo. Por ello, esta aproximación pretende aportar herramientas teóricas válidas para una reflexión crítica acerca de la cultura contemporánea y sus procesos tecnificados de producción de significado tal y como se configuran en las formas actuales de la sociedad espectacular de masas. Pretende, en definitiva, concretar, comprender las causas y calibrar los riesgos de eso que, a través de los desarrollos de Debord y Blumenberg, se desvelará como una negación de la historicidad y la temporalidad humanas y cuyas consecuencias son, si cabe, más acuciantes en nuestro tiempo que cuando ambos autores escribieron sus obras.

Para ello, nos centraremos en comprender las distancias y comunidades de estos autores haciendo girar esta exposición en torno a tres aspectos concretos. En primera instancia, se explicará en qué sentido la noción de espectáculo puede servir como un diagnóstico epocal y hasta qué punto es asimilable a la interpretación histórica de Blumenberg. En segundo lugar, se aclarará la forma en que este orden espectacular genera en ambos casos un proceso de negación de la historia cuyas consecuencias tienen que ver con la consagración de formas nuevas y más peligrosas de poder. Por último, se verá cómo el terreno común entre ambos nos permite comprender la naturaleza de sus profundas diferencias que explicaremos en torno a la distinta valoración de la historia del ideal teórico y de su relación fundamental con la visión y las imágenes. Una diferencia que no se limita al aspecto teórico, sino que también determina sus actitudes opuestas ante ese modelo espectacular antihistórico. Mediante esa comparación final, Debord se presentará como un iconoclasta carente de un plan de futuro, mientras que la actitud contemplativa de la que hará gala Blumenberg desvelará la imposibilidad de proponer alternativas a un orden que, por lo demás, parece peligroso en grado sumo. Una profunda divergencia que, nos permite plantear las insuficiencias de sus posiciones de fondo, así como atisbar la aporía que se señala tras ellas.

\section{La caverna como espectáculo}

Así pues, la primera tarea de este escrito sería aclarar en qué sentido adoptamos la noción de espectáculo como un diagnóstico compartido y hasta qué punto este sería aceptable para una comprensión blumenberguiana de la historia. Es importante hacer notar en este punto que dicho concepto se acuña a partir de la influencia de "aquella corriente minoritaria en el marxismo que atribuye una importancia central al problema de la alienación" (Jappe, 1998: 18), la cual floreció a partir de la década de los veinte del siglo pasado. Esta filiación emparentaría La sociedad del espectáculo con el Lukács de Historia y conciencia de clase (Jappe, 1998: 34-35), pero, también, con autores de la Teoría Crítica como Marcuse o Adorno (Jappe 1999). Si bien no está exenta de matices, esta filiación intelectual sitúa al padre del situacionismo en las proximidades de una corriente filosófica de la que tanto Blumenberg, como sus coetáneos más próximos del grupo de investigación Poetik und Hermeneutik, trataron de distanciarse, en parte, como una toma de posición en el panorama intelectual de la Alemania de posguerra (Boden \& Zill, 2017: 114; Benlliure, 2015; García- Durán, 2019). De hecho, la centralidad que otorga el francés al concepto de alienación será, como iremos viendo en las próximas páginas, la diferencia teórica clave con el pensamiento blumenberguiano. Este hecho no puede pasarse por alto, aunque no por ello es imposible encontrar similitudes productivas como las que aquí se pretenden señalar. Las virtudes descriptivas de la obra de Debord transcienden su metodología y las posibles insuficiencias de su planteamiento. En la medida en que La sociedad del espectáculo describe de manera exitosa una "Weltanschauung que se ha hecho efectiva, que se ha traducido en términos materiales" (Debord, 1999: 
38) y que, por tanto, define "el momento histórico en el que estamos inmersos" (Debord, 1999: 41), supone la delimitación de un horizonte el cual, como veremos, también estaba presente para Blumenberg. A su vez, el modo en que se describe, atendiendo a las formas de creación de significado, permite señalar coincidencias inesperadas y fructíferas con la obra de un pensador como el alemán, el cual concebirá la historia como la historia del esfuerzo humano por dotar de sentido y coherencia a su experiencia y entenderá el ejercicio de su pensamiento como "disciplina de la atención a las formas de significatividad" (Heidenreich, 2005: 231).

Por lo tanto, cabe aclarar, en primer lugar, qué significa el concepto de espectáculo. Como hemos apuntado, con él no se busca analizar una instancia específica de la sociedad o de la experiencia humana; el espectáculo es algo definitorio, el rasgo esencial de un orden dominante cuyo "alfa y omega" es la separación (Debord, 1999: 46). El espectáculo emerge pronto en la historia como el lugar donde se ve representado el poder de la sociedad en su conjunto; una potencia de la cual está desposeído el particular por la división del trabajo. Su origen coincide con el nacimiento del poder y aparece en la forma de lo sagrado, en tanto "reconocimiento común, en una proyección imaginaria, de la pobreza de la actividad social real, sentida en gran medida aún como unitaria" (Debord, 1999: 46). No obstante, la aparición de una sociedad capitalista global dominada por la producción y la mercancía indica el momento de mayor alienación y, con ello, de mayor difusión y relevancia de lo espectacular. El espectáculo contemporáneo responde a una atomización absoluta de la experiencia social frente a la cual se presenta como "el monólogo autoelogioso del orden actual" (Debord, 1999: 45), como una "enorme positividad indiscutible e inaccesible" (Debord, 1999: 41) que trata de unificar la experiencia disgregada mediante la proyección de una falsa unidad imaginaria. De ese modo, el espectáculo actual refleja el grado más extremo de separación entre el poder del conjunto de la sociedad y la impotencia de los individuos, desposeídos no solo de los medios de producción, sino, incluso, de su temporalidad específica.

Para Debord, lo alienante del espectáculo es la negación de la actividad humana. El espectador es pura pasividad sumisa ante las imágenes que le muestran un orden unitario que es casi antagónico a su fragmentaria experiencia cotidiana. El espectáculo le impone la forma de temporalidad de la producción de mercancías, un tiempo unilateral y meramente cuantitativo en el cual todos los momentos son intercambiables. Esta imposición tendría una escala global e invadiría cualquier espacio de la vida cotidiana. Debord se muestra preclaro al señalar las debilidades del bloque comunista, las cuales son también sociedades espectaculares que no han podido eliminar la división de trabajo como base de su modelo económico. En un principio, el espectáculo de las "sociedades burocráticas" se presenta como "espectáculo concentrado" frente al "difuso" de las sociedades de mercado, pero su función es también la de apuntalar el poder y encubrir la impotencia del individuo ante un orden social alienado (Debord, 1999: 67 y ss.). Sin embargo, en sus Comentarios a la sociedad del espectáculo publicados un año antes de la Caída del Muro de Berlín, ni siquiera se mantiene esta diferencia; el espectáculo ha unificado sus dos formas en un modelo de "espectáculo integrado" que combina el control de los ciudadanos con la exhibición de mercancía (Debord, 1990: 18 y ss.). Por lo tanto, la sumisión al espectáculo define toda una comprensión global que representa y constituye la vida social ya que, como forma de construcción de sentido, "no es un conjunto de imágenes, sino una relación social entre las personas mediatizada por las imágenes" (Debord, 1999: 38). Adquiere así rasgos ontológicos condicionando el acceso del ser humano a la realidad y señalando, con ello, su profundidad como diagnóstico. En última instancia, el espectáculo es para Debord un "mapa de este nuevo mundo, un mapa que cubre íntegramente su territorio" (Debord, 1990: 18); caracterizado por su sumisión a la pasividad y su modelo de producción técnica como monólogo autorreferente compuesto de imágenes solidificadas.

Blumenberg, por su parte, jamás habría aceptado la premisa central del concepto de espectáculo tal y como la acuñara el francés. Como habíamos apuntado, la alienación en sentido marxista no puede ser el principal elemento de malestar social para el filósofo de Lübeck, sino que es, más bien, el resultado inevitable de la necesidad humana de delegar tareas para poder concentrarse en otras, dada la finitud y limitación intrínsecas a su existencia. Esta idea de delegación es, para Blumenberg, "una de las instituciones humanas más importantes", junto a la responsabilidad (Blumenberg, 2011b: 593). El 
hanseático le confiere una importancia central como condición de posibilidad de la historicidad humana e, incluso, la sitúa como foco en torno al cual se constituye la identidad personal en contextos sociales:

La institución de la delegación supone que constantemente el grupo se cerciore sobre lo que puede exigirle al individuo y los aspectos en que puede confiar en él. Aquí el individuo podía saber, sirviéndose de las exigencias que los otros le planteaban, qué podía esperar de sí mismo sin tener que tragárselo como un veredicto de los demás (Blumenberg, 2011b: 662). ${ }^{3}$

Así, contra lo que pensaba Debord, la historia no es para Blumenberg la crónica de la separación y desposesión humanas, sino más bien el relato de su empoderamiento, del desarrollo de su capacidad de domeñar el "absolutismo de la realidad" ante el que se encontraría el primer homínido, mediante construcciones culturales que lo distancien y estabilicen la existencia. Dicho concepto de "absolutismo de la realidad" es central en la obra tardía de Blumenberg desde que se acuñase en Trabajo sobre el mito para definir la experiencia de impotencia del primer homínido ante el horizonte indeterminado, la cual supondría el impulso originario que conducirá a generar la cultura. Se trata la experiencia de un ser que "no tenía en su mano, ni mucho menos las condiciones determinantes de su existencia y, lo que es más importante, no creía tenerlas en su mano" (Blumenberg, 2003: 11). No obstante, esta experiencia no describe un mero punto de partida sino que se torna recurrente bajo diferentes formas en los momentos en los que un determinado ordenamiento histórico dejaba de ser válido. Para Blumenberg, las "carcasas culturales" del ser humano son siempre volátiles y temporales, permitiendo finalmente entrar aquello que trataban de dejar fuera perturbando, con ello, su existencia o, en terminología fenomenológica, su "mundo de la vida". Por ello, se puede situar el absolutismo como epicentro de su comprensión de la historia. Así lo mostró Barbara Merker al señalar cómo la descripción blumenberguiana del devenir histórico se despliega en torno a una serie de variaciones en las cuales se representan cómo "hay dos situaciones extremas de las que (...) nos debemos y nos podemos alejar. 'Mundo de la vida' es el nombre de Blumenberg para uno de esos valores límite. 'Absolutismo de la realidad' es su título para el otro" (Merker 1999: 68).

Esta tarea de alejamiento del absolutismo de la realidad y de generación de una cultura como sucedáneo de la unidad primaria del "mundo de la vida" era el acicate del trabajo humano. La imposibilidad de generar un mundo estable que alejase de manera definitiva la amenaza de la otredad absoluta, "el esfuerzo por generar un mundo sin esfuerzo" (Blumenberg, 2011b: 536), era la causa de su constante desarrollo teórico y práctico. La expansión de los nuevos modos de producción, así como la aparición y triunfo de la técnica, no eran más que soluciones humanas legítimas en respuesta a esa necesidad. Estrategias exitosas hasta tal punto que se encontraban cada vez más cerca de generar una esfera cultural homeostática y, de ese modo, acabar, con el proceso histórico de elaboración de significado. Las obras tardías de Blumenberg presentan una preocupación profunda por este posible fin de la historia. Un fin que se proyecta sobre la pregunta central que dirige a toda crítica cultural: ¿Qué queríamos saber? ¿Qué sentido tenía esta prodigiosa aventura del conocimiento, cuyos resultados nos habrían producido una sensación permanente de malestar? ${ }^{4}$ Los avances técnicos habrían disminuido la presión del absolutismo de la realidad hasta el punto de casi eliminarlo como foco principal hacia el cual dirigir la intencionalidad del ser humano, esto habría generado la aparición de "digresiones" de la atención como la hipocondría o el aburrimiento (Blumenberg, 2011b: 526 y ss.). En obras como Descripción del ser humano o Salidas de caverna, se muestra este desasosiego por un cercano "mundo de instrucciones de uso" (Blumenberg, 2011b: 278), un mundo de "distonía vegetativa universal" (Blumenberg, 2011b: 536) en el que florecerían estos diagnósticos, los cuales pueden resultar menos inocuos de lo que podría parecer a

\footnotetext{
${ }^{3}$ Esta centralidad de la delegación es otro ejemplo de la notable influencia que Helmuth Plessner ejerció sobre la antropología de Hans Blumenberg. Será Plessner quien confronte de manera explícita y muy convincente los conceptos de alienación y delegación en su escrito "El problema de la opinión pública y la idea de enajenación" (Plessner 1978).

${ }^{4}$ La Kulturkritik es uno de los rivales intelectuales de Hans Blumenberg. Una categoría amplia y un tanto difusa en la que podrían entrar autores tan diversos como Lucrecio, Rousseau, Heidegger o Adorno y en la que, sin duda, habría situado a Debord. En cualquier caso, la oposición directa de Blumenberg a la crítica cultural en sus obras se centrará en sus coetáneos y, en especial, en aquellos que condenaban de una forma u otra la historia de la teoría como una desviación de alguna clase de intención originaria o substancia legitimadora. Para calibrar los motivos del malestar que genera esa respuesta crítica, se plantea la mencionada pregunta como forma de conocer las causas de una "decepción en la que nadie es capaz de decir cuáles fueron las expectativas que fueron defraudadas" (Blumenberg, 2000: 11).
} 
primera vista. ${ }^{5}$ Este escenario de malestar y pasividad, por su parte, sólo podría ser paliado por la cultura. Sin embargo, lejos de hacerlo, en el presente "la cultura de masas no permite que surjan cadenas de intención de largo aliento, (...) ya no contiene las condiciones para que puedan surgir y ya no las premia" (Blumenberg, 2011b: 534).

Así, aunque desde una perspectiva distinta, ambos autores señalan su preocupación por la pérdida de la actividad humana en un horizonte hipertecnificado y espectacularizado. Por otra parte, el escenario que propicia esta situación solo puede adquirir en Blumenberg la forma de una construcción cultural densa y autorreferente cuya estructura reúne muchos de los rasgos centrales del espectáculo. Una figura de esta clase es la que se esboza en las páginas finales de Salidas de caverna a colación de la teoría de la institución de Arnold Gehlen y que podemos definir como la caverna del eterno contento. Dicha teoría explicaba la necesidad humana de construir instituciones que le liberasen de la sobrecarga de estímulos a la que el hombre se ve sometido en su existencia. Interpretando, pues, la institución como "concepto genérico de todos los habitáculos que pudieran establecerse, materiales o espirituales", (Blumenberg, 2011a: 666), Blumenberg proyecta sobre ella un modelo de caverna platónica carente no tanto de salida como de motivación para buscarla. Se trataría de la institución definitiva, la "última y definitiva caverna" (Blumenberg, 2011a: 669), una "obra de arte total" (Blumenberg, 2011a: 143) que elimina cualquier esfuerzo de elaboración de sentido sustituyéndolo por una mera contemplación estética de las sombras. En dicho habitáculo existiría un espacio para los sofistas, aquel pasaje entre el fuego y el tabique por el cual desfilarían los portadores de los objetos que proyectan sombras, donde se sitúan los "productores de contento, de manera que aquellos a quienes tienen cautivados en un doble sentido son, a la inversa, quienes se han convertido en beneficiarios de esa laboriosidad industriosa a sus espaldas. No sólo les proporciona variedad y entretenimiento, sino ante todo confianza" (Blumenberg, 2011a: 667). Una confianza necesaria, pero que, se fundamenta en una técnica de disposición de las sombras capaz de mantener entretenidos a los cautivos. En este sentido, la caverna se transformaría en una suerte de proyección de un final espectacular de la historia en el que se desconectase la tensión permanente causada por la presencia del absolutismo de la realidad, aun cuando, a diferencia de lo que sucedía con Debord, no fuese sino el destino aciago de una necesidad antropológica ineludible.

De este modo, podemos ver que el diagnóstico epocal debordiano se asemeja a algunas imágenes y proyecciones blumenberguianas. Sin embargo, lo que presentamos con el ejemplo de la caverna no pasa de ser un esquema descriptivo puntual e, incluso, marginal en la ingente obra de Blumenberg. Si resulta interesante es porque indica la posibilidad de la convergencia que pretendemos destacar aunque, a su vez, señala una comprensión de las causas que les aleja de forma notable. Pese a ello, el ejemplo de la caverna ilustra una convicción más profunda que une a ambos autores, la preocupación por la negación de la historicidad humana al generar una esfera cerrada y sólida de experiencia que somete a la condición de espectador pasivo al individuo. Esta negación supone, como veremos a continuación, la imposición de una forma unilateral de organizar la experiencia en el tiempo, o lo que es lo mismo la aparición y consagración de un poder ilimitado que pasa por encima de las necesidades del ser humano.

\section{Negación de la historia y poder}

Las descripciones precedentes de la caverna y el espectáculo permiten comprender la forma en que éste limita la posibilidad del cambio al desincentivarlo y someter al espectador a su sucesión autorreferente de imágenes. En este sentido, todo posible futuro quedaría bloqueado. El espectáculo sería, o al menos intentaría serlo, una suerte de orden final de los tiempos cuya solidez apenas parece amenazada por grieta alguna. Sin embargo, este bloqueo no agota el sentido profundo de la negación de la historia como la comprenden ambos autores. Con esa expresión nos referimos a la privación de la temporalidad humana y de la capacidad de integrar la experiencia en el tiempo en alguna forma de sentido. En este punto es

\footnotetext{
${ }^{5}$ En Descripción del ser humano, Blumenberg hace un breve catálogo de acontecimientos relevantes del siglo XX que habrían sido asignados al aburrimiento: "Heinrich Mann ve surgir del aburrimiento la caída de la República de Weimar. (...) Hannah Arendt ve a Adolf Eichmann emerger de un 'abismo de aburrimiento'. Por último, lo que ocurrió en París en mayo de 1968 y que debería denominarse con neutralidad 'los acontecimientos' se interpretó a sí mismo en el volante 'Francia estaba aburrida'” (Blumenberg, 2011b: 593).
} 
donde se percibe de forma más nítida el significado de la separación de la que habla Debord y la función del espectáculo como falsa sutura. A su vez, también supone el núcleo de la labor historiográfica de Blumenberg tal y como la formularía en un célebre pasaje de su discurso de recepción del premio Kuno Fischer. En él se señala la necesidad de que el historiador rescate la historia "de la mediatización que del pasado hace el presente, un presente para cuyas pretensiones de relevancia y módulos de actualidad sólo vale lo que le resulta eficaz"; una tarea que no es solo una justificación del trabajo académico de una disciplina que se quiere científica, sino que es todo un ethos, en tanto resulta necesario para cumplir con "la obligación, elemental, de no dar lo humano por perdido" (Blumenberg, 1999: 171-172).

Esta coincidencia estriba en que ambos autores comparten una comprensión antropológica de la historia, es decir, una identificación de la historicidad con la esencia del ser humano. Así, Debord señala que "el hombre, el ser negativo que sólo es en la medida en que se suprime el Ser, es idéntico al tiempo" (Debord, 1999: 117), mostrando con ello no sólo el carácter de proceso de su existencia, sino la índole de su tarea histórica. Ésta puede entenderse como el esfuerzo por apropiarse de la naturaleza mediante su trabajo. Un proceder que, en su forma escindida mediante la división del trabajo, genera una alienación que se transporta a la experiencia del tiempo. Así, como sucedía con el espectáculo, la historia aparece en el momento en que surge el poder. Este es el primero en generar e imponer una organización y una dirección al tiempo. Un paso que no supone en sí una pérdida, en tanto, con ello, el hombre "se libera de la escasez de las sociedades de tiempo cíclico" (Debord, 1999: 119), aunque, a su vez, significa la primera aparición de una estructura temporal impuesta que se presenta a los particulares como "un factor extraño, como aquello que no han querido y como aquello contra lo cual se creían inmunes. Pero, por este atajo, retorna asimismo la inquietud negativa de lo humano que estaba en el origen mismo de todo el desarrollo inadvertido" (Debord, 1999: 132). Esta alienación había moldeado diferentes modos de comprensión del tiempo a lo largo de la historia: desde las formas semimíticas de las religiones monoteístas, hasta la aparición del tiempo irreversible de la producción (Debord, 1999: 117-132). La temporalidad propia de la sociedad del espectáculo. Esta conforma una sucesión alienada ya que es "un tiempo, ante todo, a la medida de las mercancías" (Debord, 1999: 132), el cual se compone de "una acumulación infinita de momentos equivalentes" (Debord, 1999: 133). De ese modo, cualquier momento particular se vacía de contenido propio quedando sólo su equivalencia cuantitativa. Con ello, se negaba la temporalidad como experiencia propia y, al tratar de anular la posibilidad del cambio, recaía en un remedo del tiempo cíclico. ${ }^{6}$ Por esa razón, el espectáculo presenta la existencia como una sucesión de momentos repetibles y recurrentes que tratan de dotar de seguridad a un espectador desposeído de la posibilidad de hacerse cargo de su temporalidad particular.

Por lo tanto, Debord comprende la historia como apropiación humana de sus condiciones de existencia, aunque se trata de una apropiación que, al producirse de forma escindida, ha dado pie a una temporalidad alienada, dirigida y orientada por otros. Los dueños de la historia pueden manejarla y guiarla, pero tratan de evitar el surgimiento de la conciencia histórica que sólo aparece cuando se generan espacios para cuestionar el orden. Es en la Atenas democrática donde Debord sitúa el nacimiento de "un razonamiento histórico que es, indisolublemente, un razonamiento acerca del poder" (Debord, 1999: 123). Esta posibilidad se negaría en la desposesión radical del espectáculo al tornarse un encubrimiento general de la contingencia del poder. Como señalará en sus Comentarios: "se creía que la historia había aparecido en Grecia, con la democracia. Puede comprobarse que desaparece del mundo con ella" (Debord, 1990: 32). De ese modo, la sociedad del espectáculo señalaba la consagración de un poder sin precedentes capaz de taponar toda alternativa. En la obra de 1967, Debord parece optimista acerca de la posibilidad de disolver este ocultamiento e implantar una utópica e indefinida sociedad de "tiempos independientes federados" (Debord, 1999: 140). Sin embargo, en sus Comentarios, se incide en el triunfo de este sistema espectacular y las consecuencias más amenazadoras de la negación de la historia. Esta eliminación no es sólo "un placentero reposo para todo poder presente" (Debord, 1990: 26), sino que a su vez acaba con todo realismo, con toda capacidad estratégica e, incluso, con toda lógica; por lo que no es capaz de ver las amenazas que ella misma genera. Así, la sociedad del espectáculo se encamina a la catástrofe de

\footnotetext{
6 "La imagen social del consumo del tiempo, por su parte, está exclusivamente dominada por los momentos de ocio y vacaciones, momentos representables a distancia y postulados como deseables, como toda mercancía espectacular. Esta mercancía se ofrece aquí, explícitamente, como el momento de la vida real cuyo retorno cíclico hay que esperar" (Debord, 1999: 136).
} 
forma ciega sin ser capaz de prevenir sus riesgos, como señala uno de los pasajes más desasosegantes de esta obra:

\begin{abstract}
La construcción de un presente en el que la misma moda, desde el vestuario a los cantantes, se ha inmovilizado, que quiere olvidar el pasado y parece no creer en un futuro, se consigue mediante la incesante transmisión circular de la información que gira sobre una lista muy sucinta de las mismas banalidades, anunciadas de forma apasionada como importantes noticias; mientras que sólo muy de tarde en tarde y a sacudidas, pasan las noticias realmente importantes, las relativas a aquello que de verdad cambia. Conciernen siempre a la condena que este mundo parece haber pronunciado contra sí mismo, las etapas de su autodestrucción programada. (Debord, 1990: 24-25).
\end{abstract}

Por su parte, al excluir la alienación como epicentro del análisis, Blumenberg no señala intenciones ocultas o apropiaciones interesadas que determinen el desarrollo histórico. Las proyecciones de un final de la historia se basan, como veíamos, en el agotamiento de una tensión motora causado por su disolución definitiva. Si bien esto impide proponer una solución revolucionaria, no es menos cierto que tiene consecuencias muy similares para la relación del ser humano con la existencia y el poder a las que tenía la negación de la historia para Debord. La apropiación del pasado por las fórmulas de éxito del presente conlleva la sacralización de estas últimas, un empoderamiento ante el cual la posición de Blumenberg es la de tratar de mostrar la contingencia de cualquier forma de orden. En este sentido, el filósofo hanseático señala, con una sentencia que podría haber suscrito el francés, que "la historia es para el poder puro y duro un talón de Aquiles" (Blumenberg, 2003: 24) ya que evidencia las limitaciones de su dominio e indica y prefigura la posibilidad de alternativas. En este sentido, la deshistorización es la antesala de un poder omnímodo que no solo hace disfuncionales las condiciones antropológicas básicas programadas para el cambio, sino que, a su vez, somete a la existencia a parámetros de rendimiento cuantitativos que no atienden a las capacidades humanas.

Este proceso tiene otra consecuencia similar a la que tendría la espectacularización en Debord. Si, para éste, el tiempo espectacular ha de proyectar una forma mítica y encubridora de temporalidad que genera una confianza ficticia, en el caso de Blumenberg, la negación de la historia indica la aparición de una remitificación cuyas consecuencias no son menos conflictivas. Uno de los errores más frecuentes para los coetáneos de este autor fue interpretar sus obras sobre el mito como una suerte de apología o, incluso, como una propuesta de restauración del mito. Si bien en Trabajo sobre el mito se señala que el mito es "un trabajo de muchos quilates del logos" (Blumenberg, 2003: 20), esto no se debe interpretar como la afirmación de su necesidad inevitable. La apuesta de Blumenberg no es por un nuevo politeísmo, entendido como la proliferación actual de un pluralismo de relatos que sugiere Marquard en su "Elogio del politeísmo", mencionándole de forma equivocada como aliado (Marquard, 2000: 101 y ss.; GarcíaDurán 2019), sino que se centra en el valor de los relatos míticos en tanto figuras de la significatividad capaces de producir variaciones diversas adaptadas a diferentes momentos históricos. El mito es el primer paso en un proceso de alejamiento del absolutismo de la realidad que provoca en última instancia la aparición de la historia. La virtud del mito griego en particular proviene no sólo de su politeísmo, que depotencia el poder en esferas de acción asignadas a deidades distintas, sino de su carácter antidogmático, lúdico y artístico capaz de generar incontables variaciones por sus particulares virtudes semánticas. Esto se debe a que los mitos cuentan con su propia historicidad. El mito griego que nos habría llegado sería, incluso en sus versiones más antiguas, el producto de una selección prolongada en el tiempo cuya protohistoria Blumenberg proyecta. A través de su puesta a prueba en las competiciones de rapsodas, se habrían mantenido aquellos elementos más exitosos entre el público. Así, gracias a un paciente "darwinismo de la verbalidad" (Blumenberg, 2003: 186), las versiones conocidas de los mitos habrían podido convertirse en elementos centrales de la construcción de significatividad humana y se habrían transmitido a lo largo de la historia, trasladándose y aplicándose a diferentes conceptos de realidad a lo largo del tiempo.

Esto, sin embargo, no quiere decir que el politeísmo mítico sea una forma más adecuada de construcción de significado que el conocimiento racional. De hecho, la mayor virtud del mito griego para el filósofo de Lübeck fue haber permitido el paso posterior hacia un modelo explicativo que eliminase el factor emocional del relato. Por eso, con el avance de la racionalización en las sociedades científico-técnicas 
del presente se anuncia el fin del mito. Un fin que no se debe a la certificación de su carácter irracional, sino al desgaste histórico de su significado. Un ejemplo de este proceso sería el vaciamiento semántico del arcoíris que, en su día, pudo simbolizar la alianza entre Dios y su Creación: "No se podrá decir que esto (la consagración de la alianza) es una explicación del arcoíris, que ha podido ser rápidamente sustituida, en un estadio superior del saber científico, por una teoría física. La teoría sólo ha conseguido que este fenómeno, cuya naturaleza ahora ha sido científicamente calada, haya perdido la significación que antes tenía para el hombre" (Blumenberg, 2003: 290-291). El fin del mito significa su inevitable pérdida de significado en un mundo desencantado, pero no hace deseable una nueva remitificación que sólo puede producirse a cambio de renunciar a lo aprendido y regresar a una respuesta emocional primaria ante la experiencia. No obstante, como se señala en Trabajo sobre el mito, esta regresión es un peligro acechante oculto en el proceso de negación de la historia:

\footnotetext{
Toda posibilidad de remitificación reside en la ahistoricidad: sobre un espacio vacío es más fácil proyectar señales que indiquen un giro hacia lo mítico. Por eso, la desescolarización de la historia no representa tanto un fallo de planificación o una errónea comprensión de las cosas como un síntoma alarmante que quiere decir que o bien hay ya una mitificación en marcha o bien la pérdida de conciencia histórica forzará su advenimiento. Es posible que de la historia no podamos aprender otra cosa que el hecho de que tenemos historia; pero esto ya obstaculiza que nos sometamos al mandato de los deseos (Blumenberg, 2003: 112113).
}

Por su parte, Debord parecería distanciarse de la condena blumenberguiana de los deseos, ya que, para él, la liberación supone su cumplimiento y no su racionalización. Aun así, esta posibilidad pasa por "hacer el mundo ante todo más racional, que es la primera condición para hacerlo más apasionante" (Debord, 2006: 313). La utopía de Debord se basaría en generar un mundo en el que los deseos pudiesen realizarse de forma activa y no se proyectasen como representaciones imaginarias separadas ante el espectador pasivo. Blumenberg, por el contrario, nunca se dejó llevar por ninguna tentación revolucionaria y se distanció de forma explícita de cualquier forma de apelación a la acción frente a la reflexión. Antes bien, su actitud es resignada ante la aparición de esa formación estabilizadora. Dado que la creación de un mundo plenamente administrado es el cumplimiento de una necesidad antropológica, no se puede identificar con un grupo o clase de individuos que combatir. Al tratarse del éxito en el despliegue de unas fuerzas humanas básicas la única actitud posible parece ser la resignación, una forma de "ilustración sin ilusiones con una resignada aceptación de la pérdida" como la calificase Franz Josef Wetz (1996: 147). Una diferencia de actitud entre el revolucionario y el académico que entronca, como se mostrará a continuación, con la consideración que ambos tendrán de la actividad teórica como factor histórico del ser humano.

\section{Conclusión: Iconoclastas y contempladores}

Pese a las similitudes descriptivas que hemos indicado, las implicaciones de la brecha teórica que establece la centralidad de la alienación en el análisis de Debord se extienden por todas partes. En especial en lo que atañe a sus respectivas concepciones de la historia de la teoría y de su responsabilidad en la aparición de un sistema espectacular. Para Debord "el espectáculo es heredero de toda la debilidad del proyecto filosófico occidental, que no consistió sino en una interpretación de la actividad humana dominada por las categorías del ver" y, por ello, como consagración de la esfera de las imágenes, "filosofiza la realidad" al transformar el mundo en un "universo especulativo" (Debord, 1999: 43-44), en el cual la separación se convierte en norma. Una interpretación que trae reminiscencias evidentes de la condena heideggeriana de la presencialidad que había dirigido la historia de la metafísica y que se opone de forma diametral con la relevancia antropológica que Blumenberg confiere a la visibilidad. Para éste, el paso al bipedismo y la consiguiente apertura de un horizonte ante los ojos será el rasgo específico del ser humano destacado en su antropología fenomenológica póstuma. Como ya se señalaba a colación del mito, la humanidad surge y solo puede persistir si es capaz de codificar ese horizonte indefinido y otorgarle coherencia y sentido. La teoría sería la cumbre del esfuerzo humano por lograr una distancia con la realidad que le permitiese contemplarla de forma desinteresada. Se puede decir, por lo tanto, que el distanciamiento es en este caso el factor determinante en la historia de la especie (Borck, 2015). Un esfuerzo cuya puesta en valor implica la legitimación de una historia de la teoría que no es sino el 
esfuerzo por habérselas con toda forma de absolutismo mediante su alejamiento y el posterior intento de comprenderlo.

Aquí se puede situar la importante distancia entre el revolucionario y el contemplador resignado, entre aquel que entiende la historia como un proceso de alienación y quien la interpreta como el cumplimiento de una necesidad de seguridad. Libertad es para Debord la liberación de constricciones para la acción humana, la apertura de la posibilidad de una creatividad que transciende los códigos y normas habituales del arte, también basados en la separación, apelando a una recreación artística de las condiciones de vida. Su radical exigencia revolucionaria de "una ruptura incondicional con todos los elementos del mundo circundante, tanto en el pensamiento como en la vida" (Jappe, 1998: 72) comprometió casi cualquier causa en la que se vio implicado y redujo sus posibilidades de expansión. Esto se debe a que en ella hay poco más que un compromiso irrevocable con el derribo de lo existente (Debord, 1998: 16) que, por otra parte, no señala posibles alternativas. Dicha actitud emparienta a Debord con el tipo intelectual del gnóstico que aparece de forma recurrente en la obra de Blumenberg, ${ }^{7}$ aquél que ve el presente irreformable y prefiere destruirlo en su totalidad. Uno de los rasgos de este gnosticismo es su falta de pregnancia, su carencia de significado para la vida cotidiana. Podría decirse que la escasa existencia y menguada aportación duradera a la cultura de la Internacional Situacionista, así como sus indefinidas y utópicas propuestas revolucionarias son una muestra de la dificultad de cualquier programa gnóstico para generar estructuras e instituciones persistentes. La indeterminación del propio concepto de situación o la antedicha propuesta de una unión de tiempos libres no articulan programa viable alguno ya sea político o artístico. ${ }^{8}$ La ambivalente relación de Debord con la teoría cuya importancia revolucionaria nunca niega (Jappe, 1998: 99 y ss.), pero limita a una función estratégica, se centra en la delimitación del contrincante a cuya caída sucederá un horizonte indeterminado, una página en blanco donde realizar los deseos.

La actitud del iconoclasta gnóstico es semejante a aquel que propone la salida irreflexiva de la caverna. Una propuesta cuya desmesura "se palpa en la osadía de consentir en sacrificar lo dado sin la más mínima contrapartida" (Blumenberg, 2011a: 138). Un personaje que no es, para Blumenberg, mucho mejor que el sofista que regulaba de forma técnica la sucesión de sombras en la variación de la caverna basada en Gehlen. Frente a ellos, la figura que mejor señala la posición de Blumenberg ante el discurrir de las apariencias es la del fenomenólogo de las sombras. Aquellos campeones en el arte de discernirlas que se entrenan en comprender e interpretar mejor las imágenes; "una figura de convergencia entre el talante teórico de los antiguos y la moderna ética de la laboriosidad" (Blumenberg 2011a: 586) que quiere recuperar la actividad como trabajo teórico y no como creación sin limitaciones, pero que se ve del mismo modo amenazada por la negación de la historia, al desaparecer su capacidad de comprender la sucesión, así como los estratos que configuran la estructura de ese desfile. Como apuntábamos, la cultura de masas dificulta o, incluso, hace imposible la tarea del fenomenólogo de las sombras, quien, no obstante, no puede sino resignarse a describir lo dado y no deducir de ello lo venidero. Una actitud que, por otra parte, nunca acaba de liberarse la sospecha de inmoralidad del espectador que el mismo Blumenberg teorizase (Blumenberg 1995).

Si damos por válida la descripción del espectáculo como diagnóstico, las figuras del contemplador y del iconoclasta que se han esbozado resultan insatisfactorias. Señalan, en cierto modo, una aporía vívida en nuestros días: la imposibilidad de pensar una alternativa a un orden que apenas deja entrever nada de lo

\footnotetext{
${ }^{7}$ La preocupación por la gnosis en Blumenberg no se limita a su importancia historiográfica para el argumento de La legitimidad de la Edad Moderna, su mera acepción acarrea una dimensión crítica. La permanencia de formas de pensamiento gnósticas había sido puesta de relieve por Hans Jonas y Eric Voegelin desde diferentes perspectivas. El primero, el gran estudioso del movimiento gnóstico antes de la II Guerra Mundial, había resaltado las similitudes entre éste y la filosofía de Heidegger que denotaban analogías en "tipos de existencia de ambas partes" (Jonas, 2003: 338). Por su parte, Voegelin calificaría de gnósticos a los movimientos políticos totalitarios, incidiendo sobre todo en el comunismo, a los cuales acusaba de practicar una "inmanentización falaz del eschaton cristiano" (Voegelin, 2006: 149). Estas ideas están en el trasfondo ideológico que convertirá a la noción de gnosis en un "concepto de litigio" [Streitbegriff] (Buch, 2014: 88) a partir de los años 60.

${ }^{8}$ En el Rapport, considerado el programa de la Internacional Situacionista, las situaciones se definen como "ambientes colectivos, un conjunto de impresiones que determina la cualidad de un momento" (Debord, 2006: 324). Un proceder sobre el cual se ofrecen escasas indicaciones en tanto que su forma pasa por la mera innovación artística, por "la creación de nuevas leyes de disposición de los objetos" (Debord, 2006: 322), cuyo objetivo general es "encontrar nuevas pasiones" (Debord, 2006: 328).
} 
que queda fuera de sus límites, la vivencia más patente del proceso de negación de la historia que hemos descrito. Ninguno es capaz de ir más allá de la densidad de las imágenes, aunque ambos plantean un peligro implícito en su horizonte presente: una cultura que ha perdido los anclajes con la realidad existencial del ser humano no puede sino encubrir la irracionalidad del poder que la sustenta. Más allá de la dificultad en atravesar la densidad de las imágenes que se presentan, el peligro estriba en que el afuera del orden acabe por arrollar a quienes se encuentran en su interior sin que estos sean capaces de comprender por qué, ni menos preverlo. Un riesgo que, en ambos casos, parece menos una mera constatación de el fin de un tiempo histórico que una amenaza para la propia autoconservación de la especie.

\section{Referencias}

Benlliure, R. (2015). "Blumenberg y la Teoría Crítica". En Oncina Coves, F. \& García- Durán, P. Hans Blumenberg. Historia In/conceptual, antropología y modernidad. Pre- Textos. Valencia

Blumenberg, H. (1995). Naufragio con espectador. Traducción de Jorge Vigil. Visor. Madrid

Blumenberg, H. (1999). Rememorando a Ernst Cassirer. Las realidades en que vivimos. Traducción de P. Madrigal. Paidós. Barcelona.

Blumenberg, H. (2000). La legibilidad del mundo. Traducción de P. Madrigal. Tecnos. Madrid.

Blumenberg, H. (2003). Trabajo sobre el mito. Traducción de P. Madrigal. Paidós. Barcelona.

Blumenberg, H. (2011a). Salidas de Caverna. Traducción de J. L. Arántegui. Visor. Madrid.

Blumenberg, H.(2011b). Descripción del ser humano. Traducción de G. Mársico. Fondo de Cultura Económica. Buenos Aires.

Blumenberg, H. \& Taubes, J. (2013). Briefwechsel 1961-1981 und weitere materialen. Suhrkamp Verlag. Frankfurt.

Boden, P. \& Zill, R. (2017). Poetik und Hermeneutik im Rückblick. Wilhelm Fink. Múnich.

Borck, C. (2015). "La historia como distanciamiento. Hans Blumenberg entre la antropología y la epistemología histórica”. Traducción de P. García- Durán. Oncina Coves, F. \& García- Durán, P. Hans Blumenberg. Historia in/conceptual, antropología y modernidad. Ed. cit.

R. Buch (2014). “Gnosis”. En Buch, R. \& Weidner, D. Blumenberg lesen. Ein Glosar. Suhrkamp. Fráncfort.

Debord, G. (1990). Comentarios sobre la sociedad del espectáculo. Traducción de C. López y J.L. Capella. Anagrama. Barcelona.

Debord, G. (1998). Panegírico. Traducción de T. González López \& A. Fernández Savater. Acuarela libros. Madrid.

Debord, G. (1999). La sociedad del espectáculo. Traducción de J.L. Pardo. Pre- Textos. Valencia.

Debord, G. (2006). Rapport sur la construction des situations. Oeuvres. Gallimard. París.

García- Durán, P. (2019). El mito como concepto polémico. El trasfondo político del debate sobre el mito en Poetik und Hermeneutik. Conceptos Históricos. 5 (7).

Heidenreich, F. (2005). Mensch und Moderne bei Hans Blumenberg. Fink. Múnich. 
Jappe, A. (1998). Guy Debord. Traducción de L.A. Berlow. Anagrama. Barcelona.

Jappe, A. (1999). Sic Transit Gloria Artis: "The End of Art" for Theodor Adorno and Guy Debord. SubStance. Vol. 28. No. 3. Issue 90: Special Issue: Guy Debord.

Jonas, H. (2003). La religión gnóstica. El mensaje del Dios extraño y los comienzos del cristianismo. Traducción M. Gutiérrez. Siruela. Madrid.

Marquard, O. (2000). Elogio del politeísmo. Adiós a los principios. Traducción de E. Ocaña. Alfons el Magnànim. Valencia.

Merker, B. (1999) Bedürfnis nach Bedeutsamkeit. Zwischen Lebenswelt und Absolutismus der Wirklichkeit. Wetz, F.J. \& Timm, H. (eds.). Die Kunst des Überlebens. Nachdenken über Hans Blumenberg. Suhrkamp. Fráncfort.

Plessner, H. (1978). Más acá de la utopía. Traducción E. Garzón Valdés. Alfa. Buenos Aires.

Voegelin, E. (2006). La nueva ciencia de la política. Una introducción. Traducción de J. Ibarburu. Katz. Buenos Aires.

Wetz, F.J. (1996). Hans Blumenberg. La modernidad y sus metáforas. Traducción de M. Canet. Alfons el Magnànim. Valencia. 